\title{
Torsional Vibration Response of Turbogenerator (TG) using Solid Finite Elements
}

\author{
[Ganesh Dacharum, Kshitij Gupta]
}

\begin{abstract}
To improve turbogenerator (TG) rotor design,Torsional vibration analysis is necessary. Torsional vibration of turbogenerator shaft occurs due to the electrical unbalances and disturbances in the generator (short circuits, line switching, faulty synchronizing etc). In the present paper 3-Dimensional (3D) solid finite element (FE) is used in FE software ANSYS, to evaluate the natural frequencies and dynamic response due to transient torque excitations. The 3D solid model eliminates the assumption inherent in the 1-Dimensioanl (1D) model, and therefore provides more realistic results. The simulation of transient torque disturbances on the rotor system caused by different short circuit faults has been performed on 3D model and the response is obtained. The computational time required for the analysis by 3D solid model is relatively more. However the 3D solid FE model provides information about all modes including the shaft and disc coupling effect. The response calculated through analytical method, is also presented. The alternating shear stress values obtained due to three phase short circuit fault are found to be more compared to stresses obtained due to line to line, and line ground short circuit fault. It is concluded that 3D modeling using solid finite elements gives more realistic and complete results, and thereby provides a superior TG design capability.
\end{abstract}

Keywords-Torsional vibrations; Turbogenerator rotor; Short circuit faults; Solid finite elements.

\section{Introduction}

Turbogenerator (TG) is a turbine directly connected to a generator for the generation of electric power. The basic requirement for the TG is to operate in "synchronism" condition, which means that the mechanical speed must be equal to its electrical speed(frequency). During synchronism condition, ideally there should be no torque disturbances on the rotor. However torque disturbance may occur under certain operating conditions, which would result in torsional vibrations of TG. Disruption to steam flow, and increase in the demand for power are slow changes controlled by turbine governing mechanism or external control loops. However electrical faults such as short circuit and line switching cause abnormal torque disturbances on the rotor, which may induce high torsional vibrations in the rotor leading to failure. To prevent such a failure, torsional vibration analysis is required to obtain response, natural

Ganesh Dacharum

Mahindra Research Valley (MRV), Chennai, India

Kshitij Gupta

Indian Institute of Technology, Delhi, India frequencies and damping characteristics to enable a reliable dynamic design of the system. To predict the dynamic behavior of rotor system, analytical methods as well as numerical approximation methods like finite element (FE) are already available, and two approaches have been used to model the system; lumped mass approach and consistent mass approach. In finite element method for rotor dynamics, Timoshenko shear correction factor and gyroscopic effects are taken into account. However beam element based FE models suffer from several disadvantages: 1. these are less realistic since real rotor systems are not one dimensional, 2. several coupling effects cannot be modeled, 3. centrifugal effects of shaft and mounted parts cannot be accounted for. An accurate rotor dynamic analysis needs solid models for the rotors. These models eliminate the disadvantages of beam models. In present study, torsional vibrations due to abnormal short circuit torque excitation, are analyzed using solid FE model and the same is validated with the analytical models.

\section{Past Research Work}

\section{A. Literature Review}

The shaft models commonly used fall into two categories, the concentrated mass model and the distributed mass model. In concentrated mass model, shaft is divided into a number of lumped masses connected by ideal massless springs, and then the multiple mass-spring (lumped parameter) systems are formed. Because of its simplicity, this kind of model is extensively used [1] in the research on torsional vibration. Zhang et al., [2] established a 300MW turbogenerator step-shaft model of rotor system which has consecutive distributed parameters and calculated turbogenerator free torsional vibration by using onedimensional wave equation. Qing He, Dongmei Du [3] proposed Increment Transfer Matrix (ITM) method for torsional response calculation of turbogenerator shafts. This method combines Riccati transfer matrix method with the Newmark- $\beta$ step-by-step integral method. By the ITM method, the transient torsional vibration response of turbogenerator shafts at critical cross-sections could be calculated. Using lumped mass model they calculated torsional vibration response of 200MW turbogenerator shaft due to the faulty operation. Smith, Mykura and Cudworth [4] proposed a method for evaluation of a variable damping coefficient which depends on the property of the shaft material when undergoing high stress cyclic variations. Rotor systems in real world have complex geometries, so it is difficult to model them analytically. Finite element methods are used extensively to analyze such systems. Rotating shafts are typically modeled by line or beam elements. These beam elements are formulated from classical beam theory with a basic assumption that "plain sections remain plain during bending". 
However, when the rotors have abrupt changes in diameter, this assumption is not valid because of local distortions occurring near these sections. This results in an overall increase in bending flexibility of the shaft. To eliminate this effect in the beam theory Stephenson, Rouch and Arora [5] modeled rotating shafts using solid axisymmetric elements. Yu, Craggs and Mioduchowski [6] modeled the shaft using solid finite elements for an orbiting shaft. Rao and Sreenivas [7] modeled asymmetric rotors with dissimilar moment area using solid finite elements. For non-uniform shafts such as tapered or stepped ones, these models give reliable and accurate results.

\section{Torsional Vibration Analysis (TVA) Through Analytical Method}

Torsional vibrations are the leading cause of failures in turbo machinery drive trains. Accordingly, a thorough torsional vibration analysis should be included as an integral part of the design of turbo machine. A steam turbine is a complex mechanical system consisting of rotors connected by means of couplings, Fig. 1 [1]. Rotors are constituent parts of the high pressure turbine (HPT), medium pressure turbine (MPT), and lower pressure turbine (LPT), and on each, the mechanical and thermal loading conditions are different.

\section{A. Lumped Parameter System Models}

The common procedure for modeling of shaft system of turbo generator is that, firstly the whole shaft is divided into stepped shaft according to its geometry and shapes; then the special parts in each section, such as laminae and couplings, are converted into stepped shafts with equivalent Torsional rigidity and moment of inertia. Here a simplified model of a turbine shafting in the form of vibrating system with four degrees of freedom (Fig. 2) is presented. $\boldsymbol{I}_{\mathbf{1}}, \boldsymbol{I}_{\mathbf{2}}$ and $\boldsymbol{I}_{\mathbf{3}}$ represent moments of inertia of masses of HPT, MPT and LPT respectively. $\boldsymbol{I}_{\mathbf{4}}$ is a Sum of moments of inertia of masses of generator parts. Stiffness value $K_{1}, K_{2}$ and $K_{3}$ are defined as the inverse of the sum of compliances of the shafting structural elements between geometrical centers of HPT, MPT, LPT, and Generator. For the turbo generator under consideration [1], these parameters have following values: $\boldsymbol{I}_{\mathbf{1}}=429.6 \mathrm{kgm}^{2}, \quad \boldsymbol{I}_{\mathbf{2}}=2779 \mathrm{kgm}^{2}, \quad \boldsymbol{I}_{\mathbf{3}}=6158 \mathrm{kgm}^{2}$, and $\boldsymbol{I}_{\mathbf{4}}=3560 \mathrm{kgm}^{2}, \boldsymbol{K}_{\mathbf{1}}=4.78 \times 10^{7} \mathrm{Nm} / \mathrm{rad}, \boldsymbol{K}_{2}=5.2 \times 10^{7}$ $\mathrm{Nm} / \mathrm{rad}$ and $\boldsymbol{K}_{3}=7.23 \times 10^{7} \mathrm{Nm} / \mathrm{rad}$.

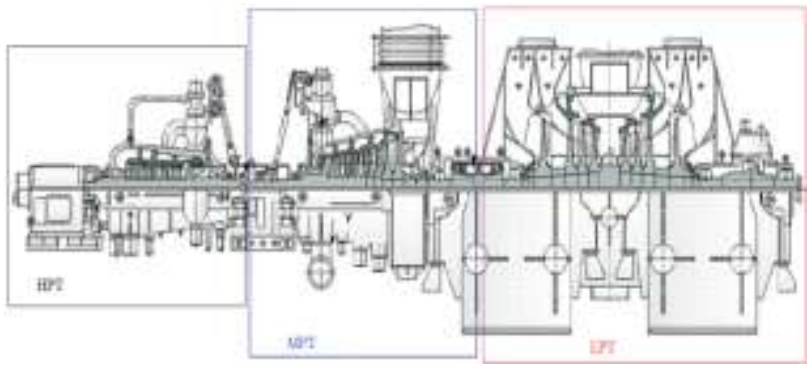

Figure 1. Model K-200-130 steam turbine (210MW Power) [1]

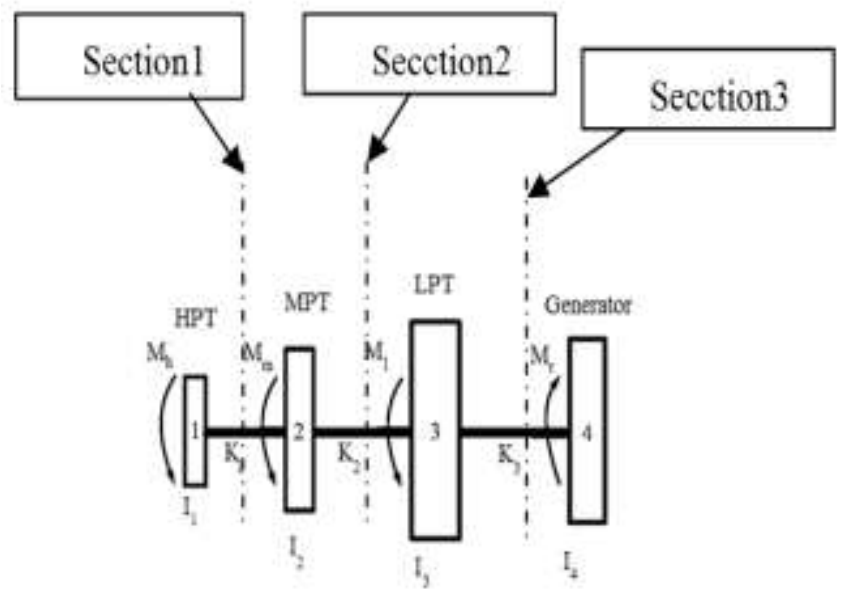

Figure 2. Simplified model of steam turbine shafting: (1) HPT; (2) MPT; (3) LPT; (4) Generator [1]

Since the system shown in Fig. 2 is a degenerated system, we observe that the first natural frequency is zero which corresponds to a rigid body rotation. The second, third and fourth natural modes have one, two and three node (Zero displacement) points respectively.

TABLE 1. TORSIONAL NATURAL FREQUENCIES

\begin{tabular}{|c|c|}
\hline S. No. & Frequency (Hz) \\
\hline 1 & 0 \\
\hline 2 & 20.008 \\
\hline 3 & 30.001 \\
\hline 4 & 54.782 \\
\hline
\end{tabular}

\section{B. Transient Torsional Vibration Analysis}

An important factor in the design of rotating machines is the possibility of transient loads acting on a rotor, for example, the electrical unbalance in a generator. These transient loads can induce excessive stresses, though for a short period, which can lead to low cycle fatigue and permanent failure of shaft or some critical parts such as couplings. The system equations of motion can be written as,

$$
[I]\{\bar{\theta}\}+[C]\{\dot{\theta}\}+[K][\theta]=[M]
$$

Here, $[\boldsymbol{I}]$ is the matrix of moments of inertia of disks masses, $[\boldsymbol{K}]$ is the stiffness matrix, $[\boldsymbol{C}]$ is the damping matrix, $\{\boldsymbol{\theta}\}$ is the vector of the disks rotation angles, and $\{\boldsymbol{M}\}$ is the excitation moment vector. Proportional damping is used in the analysis. $\boldsymbol{M}_{\boldsymbol{r}}$ is the full load reaction torque acting at the generator. The reaction torque acts on the rotor system and is transient in nature. There are several methods to solve the equations to get response of system experienced by transient loads. In present work numerical integration method such as Newmark- $\beta$ method is used to solve the equations. Reaction torque is represented by magnitude, duration and form. The experience of steam turbine operation suggests that the short-circuit duration is unpredictable and can vary from a few hundredths to a few tenths of a second. Based on the paper presented by Bovsunoskii [1], the ratio between the surge magnitudes of the reaction torque $\boldsymbol{M}_{\boldsymbol{r}}$ and the total 
torque $\boldsymbol{M}_{\text {total }}$ can be between 3 to 12 i.e., $\boldsymbol{M}_{\boldsymbol{r}}=(3$ to 12$)$ $M_{\text {total }}$

Thus the magnitude of the reaction torque may presumably vary over a very wide range. Dynamic loading in the form of a short time surge of the torque is rather complicated to analyze. The full load torques on HPT, MPT, and LPT estimated from operating conditions are taken as: $\boldsymbol{M}_{\boldsymbol{h}}$ (at HPT $)=196 \times 10^{3} \mathrm{Nm}, \quad \boldsymbol{M}_{\boldsymbol{m}}($ at MPT $)=291 \times 10^{3} \mathrm{Nm}$, and $\boldsymbol{M}_{\boldsymbol{l}}($ at LPT $)=163 \times 10^{3} \mathrm{Nm}$. The full-load torque acting between turbine shafting and generator is equal to sum of above torques. Therefore the total torque $\boldsymbol{M}_{\text {total }}=650 \times 10^{3}$ $\mathrm{Nm}$. In solving the dynamic problem, the excitation moment vector $\{\boldsymbol{M}\}$ consisted of a single non- zero value equal to the reaction torque $\boldsymbol{M}_{\mathbf{r}}$, which is applied to the generator. In the calculations, its magnitude is given by

$M_{r}=\mathrm{K} \times M_{\text {total }} \times \mathrm{f}(\mathrm{t})$

Where $K$, is the coefficient varying from 3 to 12 . The form of torque surge and its duration $t_{\mathrm{m}}$ are given by the function $\mathrm{f}(\mathrm{t})$. Based on Newmark algorithm a MATLAB code is developed to find out the response i.e., rotation (vibratory) angles of disks as a function of the time. Relative rotation angles are used to calculate shear stress in rotors, which remain constant in each section of the shaft. The shear stress values are plotted with respect to time for the rotor system for different short circuit torque.

\section{TVA through ANSYS using Solid Finite Elements}

Rotors have complex geometry which makes analytical modeling extremely difficult. To evaluate the system dynamic behavior, finite element methods are used. Modeling of rotor is performed in ANSYS software, with type of element taken as solid 186. Material properties are assumed for steel, Young's modulus $\left(E=2.1 \times 10^{11} \mathrm{~N} / \mathrm{m}^{2}\right)$, Poisson's ratio $(v=0.3)$ and density $\left(\rho=7850 \mathrm{~kg} / \mathrm{m}^{3}\right)$. Modal analysis is performed on 3D finite element model (Fig. 3) in ANSYS software; as a result natural frequencies of rotor system are obtained. First four torsional natural frequencies are shown in Table 4. Fig.4 shows the mode shapes.

TABLE 2. SHAFT DIMENSIONS

\begin{tabular}{|c|c|c|}
\hline Shaft & Diameter(mm) & Length(mm) \\
\hline Between HPT and MPT & 328.341 & 1916.8 \\
\hline Between MPT and LPT & 379.165 & 3127.15 \\
\hline Between LPT and Generator & 432.992 & 3846.37 \\
\hline
\end{tabular}

TABLE 3. DisC DIMENSIONS

\begin{tabular}{|c|c|c|}
\hline Disc & Outer Diameter $(\mathbf{m m})$ & Thickness $(\mathbf{m m})$ \\
\hline HPT & 1178.5 & 290.6 \\
\hline MPT & 1710.6 & 421.9 \\
\hline LPT & 2005.7 & 494.6 \\
\hline Generator & 1798.1 & 443.4 \\
\hline
\end{tabular}

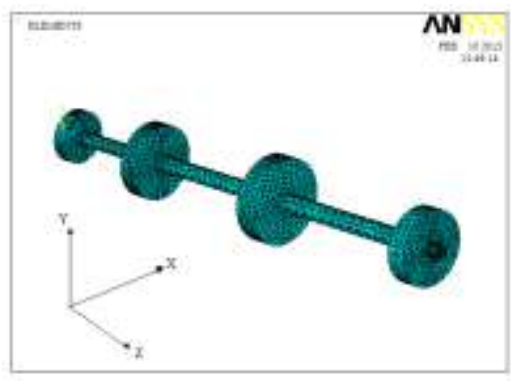

Figure 3. Finite element model of simplified 3D model of turbogenerator

TABLE 4. TORSIONAL NATURAL FREQUENCIES OBTAINED FROM ANSYS

\begin{tabular}{|c|c|}
\hline S. No & Frequency (Hz) \\
\hline 1 & 0 \\
\hline 2 & 20.008 \\
\hline 3 & 30.001 \\
\hline 4 & 54.782 \\
\hline
\end{tabular}

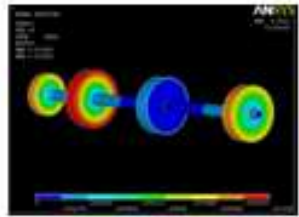

(a)

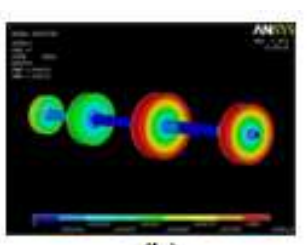

(b)
Figure 4. Mode shapes at torsional frequency (a) $20.008 \mathrm{~Hz}$ and (b) $30.001 \mathrm{~Hz}$

\section{Comparison of Results} Obtained from Analytical Method and Finite Element Method using ANSYS Software

\section{A. Natural Frequencies Comparison}

TABLE 5. TORSIONAL NATURAL FREQUENCIES COMPARISON

\begin{tabular}{|c|c|c|c|}
\hline \multirow{2}{*}{ S. No. } & \multicolumn{2}{|c|}{ Frequency (Hz) } & \multirow{2}{*}{ Error (\%) } \\
\cline { 2 - 3 } & Analytical & FEM & \\
\hline 1 & 0 & 0 & 0 \\
\hline 2 & 21.0307 & 20.008 & 4.862 \\
\hline 3 & 31.2824 & 30.001 & 4.096 \\
\hline 4 & 57.7315 & 54.782 & 5.108 \\
\hline
\end{tabular}

Torsional natural frequencies obtained from two methods, i.e., from analytical method and FEM method are compared. A difference of less than $6 \%$ is observed.

\section{B. Transient Response Comparison}

Transient torque in TG rotor is caused by various conditions of short circuiting. Specifically there are three conditions, three-phase short circuit, line to line short circuit, and line to ground short circuit. Rotor transient response due to each of these conditions is discussed below. 
Transient Response caused by Three-Phase Short Circuit Transient Torque.

Three phase short circuit fault creates most unfavorable abnormal torque disturbance on the rotor system. Fig. 5 shows the reaction torque behavior due to three phase short circuit acting on the generator. This toque contains decay terms and first harmonics. Per unit air gap torque due to three phase short circuit is given in (3)[10].

$$
f(t)=1.54 e^{-7.9 t}+10.3 e^{-10 t} \sin (\omega t)
$$

From (2), $\boldsymbol{M}_{\mathbf{r}}=\mathrm{K}$ x $\boldsymbol{M}_{\text {total }}$ x f(t). The duration of reaction torque applied on the rotor system is $0.02 \mathrm{sec}$ and the speed of the rotor is $3000 \mathrm{rpm}$. shear stress values are more in section 3 (near to Generator) as compared to section 2 and section 1 as shown in the Fig. 6 . Also the peak values of shear stresses in various shaft sections are slightly smaller by FEM method as compared to the values obtained by analytical method.

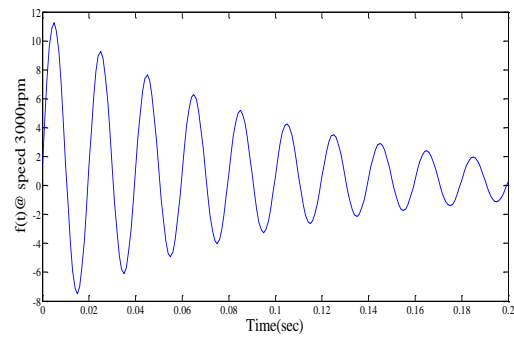

Figure 5. Nature of reaction torque due to three phase short circuit
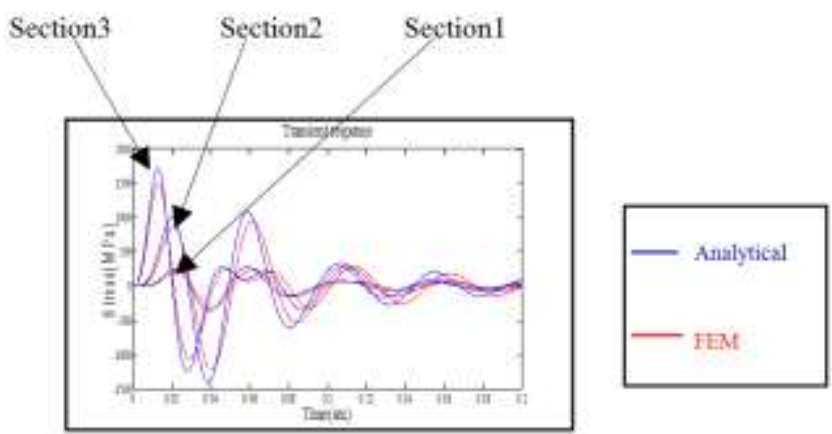

Figure 6. Transient Response on Rotor System due to Three-Phase Short Circuit Fault

\section{Transient Response caused by Line to Line Short Circuit Transient Torque.}

Line to line short circuit fault also creates unfavorable torque disturbance on the rotor system. Per unit air gap torque due to line to line short circuit is given by the (4)[10]. This torque contains decay terms, and first and second harmonics of rotational speed.

$$
\mathrm{f}(\mathrm{t})=2.07 e^{-6.2 t}+10.4 e^{-6.9 t} \sin (\omega t)-5.18 e^{-5.7 t} \sin (2 \omega t)
$$

The magnitude of reaction torque is as per (2) i.e., $\boldsymbol{M}_{\mathrm{r}}=\mathrm{K} \mathrm{x}$ $\boldsymbol{M}_{\text {total }}$ x f(t). Its duration is also taken as 0.02 sec. Fig.7 gives the shear stresses in the three shaft sections by FEM and the analytical method. The peak shear stress values are largest in Section 3.

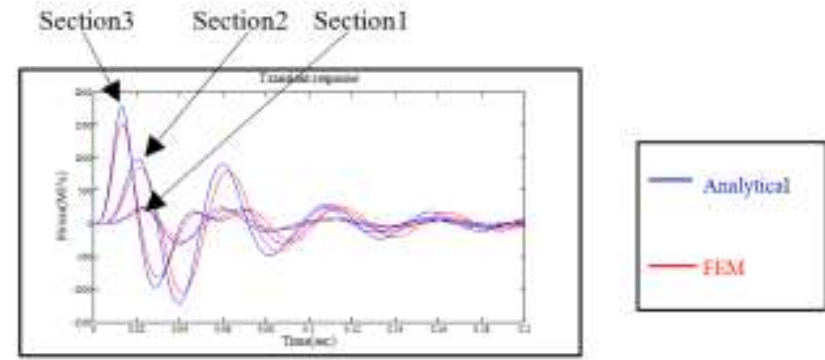

Figure 7. Transient Response on Rotor System due to Line to Line Short Circuit Fault

Transient Response caused by Line to Ground Short Circuit Transient Torque.

The expression for per unit air gap torque due to line to ground short circuit fault is as given in (5)[10]. The presence of decay terms, and first two harmonics of rotational speed, is evident. As in previous cases, duration of reaction torque applied on the rotor system is $0.02 \mathrm{sec}$ at the rotor speed of $3000 \mathrm{rpm}$.

$\mathrm{f}(\mathrm{t})=1.88 e^{-7 t}+9.5 e^{-8.3 t} \sin (\omega t)-4.75 e^{-5.2 t} \sin (2 \omega t)$

The plot of shear stresses in Fig. 8 shows a similar trend as in the previous cases. Section 3 has the largest shear stress compared to sections 1 and 2. Maximum shear stress values are induced in section 3 (nearer to generator) as compared to other sections in all the short circuit faults.

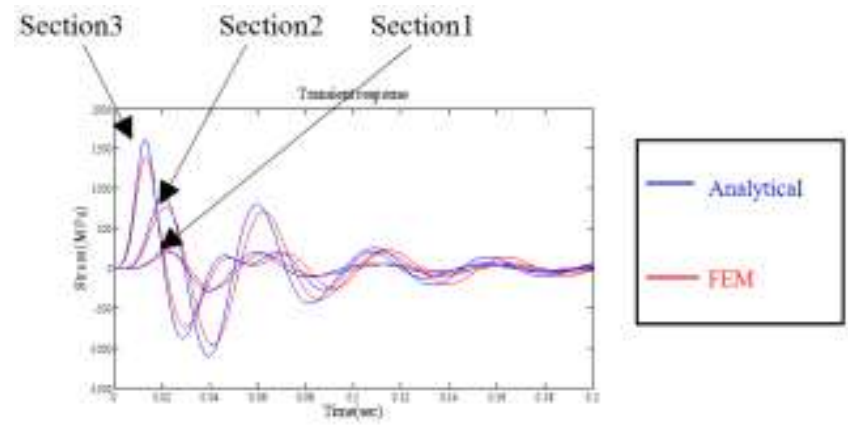

Figure 8. Transient Response on Rotor System due to Line to Ground Short Circuit Fault

\section{v. Conclusions}

Torsional vibration analysis is performed through ANSYS software using solid finite elements and results are validated with the analytical method. Torsional natural frequencies obtained from two methods show good correlation between them.

Transient response is evaluated due to different short circuit faults. The alternating shear stress values obtained due to three phase short circuit fault are found to be more compared to stresses obtained due to line to line, and line ground short circuit fault, i.e., three-phase short circuit fault is more dangerous than other short circuit faults.

3D solid finite element model gives accurate and realistic results, because it eliminates the assumption inherent to $1 \mathrm{D}$ model.

Section 3 (near to generator) experiences highest shear stresses as compared to section 2 and section 1 in all the short circuit fault transient conditions. 


\section{References}

[1] A.P.Bovsunoskii (2012): Torsional vibrations in steam turbine shafting in turbogenerator abnormal modes of operation, Strength of Materials. National University of Technology, Kiev, Ukraine. Springer science business media, Inc.2012, 10.1007/s11223-0129370-9.

[2] Zhang Jun-hong, Hao Zhi-yong, Fu Lu-hua, Ding Hua-li (2001): Modelling and calculation of the natural frequency of $300 \mathrm{MW}$ turbogenerator rotor shaft systems. Tianjin University Vol. 7 No.2

[3] Qing he, Dongmei Du (2010). Modelling and calculation analysis of torsional vibration for turbine generator shafts. Journal of information and Computational Science 7:10 (2010) 2147-2182.

[4] J.R. Smith, Mykura and C.J. Cudworth (1986): The effect of hysteretic damping on the turbogenerator shaft torsional oscillations. IEEE Transactions on Energy Conversion, Vol.EC-1, No. 1, March 1986.

[5] R.W. Stephenson, K.E. Rouch and R. Arora (1989): Modelling of rotors with axisymmetric solid harmonic elements. University of Kentucky. Journal of Sound and Vibrations (1989) 131 (3), 431-443.

[6] J. Yu, A. Craggs and A. Mioduchowski (1999): Modelling of shaft orbiting with 3D solid finite elements. International Journal of Rotating Machinery 1999, Vol. 5, No.1 Pp 53-65.

[7] J.S. Rao and R. Sreenivas (2003): Dynamics of asymmetric rotors using solid models. International Gas Turbine Congress 2003 Tokyo, November 2-7, 2003 (IGTC2003Tokyo TS-016).

[8] Wang-fan Li, Dan-mei XIE, Yong QIAN, Xian Zhao, Sun CAI, Youmin Hou: Calculation of rotors torsional vibration characteristics based on equivalent diameters and stiffness. School of Power and Mechanical Engineering, Wuhan University, Wuhan, China.

[9] Mechanical vibrations by S.S Rao fifth edition.

[10] G.D. McCann, C.E. Warren, H.E. Criner (1945): Determination of Transient Torques in Turbine Generator by means of Electrical Mechanical analogy. IEEE Transactions 51, February, 1945.

[11] Joakim Samuelsson (2009): Rotor dynamic analysis of 3D modelled Gas turbine rotor in ANSYS. Department of Management and Engineering, GRCRM, Siemens Industrial Turbo machinery AB.

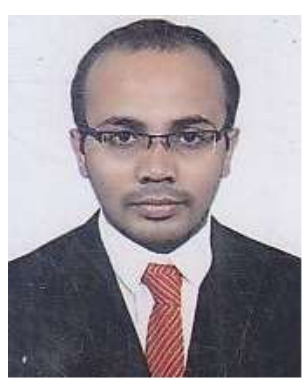

Ganesh Dacharum is presently working in the Mahindra Research Valley (MRV), Chennai, India. In the past he was with Escorts Ltd., Faridabad. He received his B.Tech. (2011) from JNTU Hyderabad and his Master's degree from IIT Delhi in the year 2013. He specializes in the field of Vibrations and Mechanical Design.

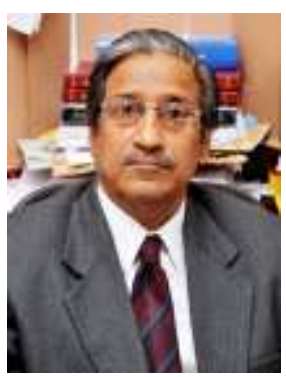

Dr. K. Gupta is professor of Mechanical Engineering at IIT Delhi. He received his B.Tech. (1972) and M.Tech (1974) degrees from IIT Kharagpur, and his Ph.D. degree in 1979 from IIT Delhi. He has taught at IIT Roorkee and at IIT Delhi for more than 35 years. His teaching and research interests are in Vibrations, Acoustics, Rotor Dynamics, Mechanical Design, and Composite and smart material applications. He has co-authored a book on 'Mechanical Vibrations'. He is a fellow of Indian National Academy of Engineering (INAE), and member of IFToMM Technical Committee on Rotor Dynamics (TCRD). 